\title{
Toll-Like Receptor-Based Strategies for Cancer Immunotherapy
}

\author{
Saghar Pahlavanneshan $\mathbb{D}^{1}$ Ali Sayadmanesh $\mathbb{D}^{1},{ }^{2}$ Hamidreza Ebrahimiyan $\mathbb{D}^{2}$, \\ and Mohsen Basiri $\mathbb{D D}^{2}$ \\ ${ }^{1}$ Functional Neurosurgery Research Center, Shohada Tajrish Comprehensive Neurosurgical Center of Excellence, Shahid Beheshti \\ University of Medical Sciences, Tehran, Iran \\ ${ }^{2}$ Department of Stem Cells and Developmental Biology, Cell Science Research Center, Royan Institute for Stem Cell Biology \\ and Technology, ACECR, Tehran, Iran
}

Correspondence should be addressed to Mohsen Basiri; mohsenbasiri@gmail.com

Received 26 March 2021; Revised 28 April 2021; Accepted 9 May 2021; Published 24 May 2021

Academic Editor: Tomasz M. Karpi ski

Copyright (C) 2021 Saghar Pahlavanneshan et al. This is an open access article distributed under the Creative Commons Attribution License, which permits unrestricted use, distribution, and reproduction in any medium, provided the original work is properly cited.

\begin{abstract}
Toll-like receptors (TLRs) are expressed and play multiple functional roles in a variety of immune cell types involved in tumor immunity. There are plenty of data on the pharmacological targeting of TLR signaling using agonist molecules that boost the antitumor immune response. A recent body of research has also demonstrated promising strategies for improving the cell-based immunotherapy methods by inducing TLR signaling. These strategies include systemic administration of TLR antagonist along with immune cell transfer and also genetic engineering of the immune cells using TLR signaling components to improve the function of genetically engineered immune cells such as chimeric antigen receptor-modified T cells. Here, we explore the current status of the cancer immunotherapy approaches based on manipulation of TLR signaling to provide a perspective of the underlying rationales and potential clinical applications. Altogether, reviewed publications suggest that TLRs make a potential target for the immunotherapy of cancer.
\end{abstract}

\section{Introduction}

Cancer immunotherapies have been of great promise for the treatment of different types of cancer. Checkpoint inhibitors such as anti-PD-1/PDL-1 and anti-CTLA4 antibodies that can treat solid cancers through activation of an antitumor immune response are now approved by regulatory organizations in Europe and the US [1]. Cell-based immunotherapies such as chimeric antigen receptor (CAR) $\mathrm{T}$ cells have also shown to be strikingly effective in treating refractory or relapsed hematopoietic malignancies [2]. These successful experiences showed that triggering an efficient antitumor immune response could be applied as an effective therapy for cancer. To this end, exploiting relevant immunostimulatory mechanisms is of great importance for the development of new potent immunotherapy strategies. Toll-like receptors (TLRs) are a class of molecules that play such immunostimulatory roles in many immune cells involved in cancer immunity.
TLRs are a well-known family of pattern recognition receptors that recognize conserved structures in pathogens. The extracellular TLR groups (TLR1, TLR2, TLR4, TLR5, TLR6, and TLR10) are expressed on the plasma membrane while intracellular TLR groups (TLR3, TLR7, TLR8, and TLR9) are expressed in the endosome and endoplasmic reticulum, whereas TLR4 is found both on the plasma membrane and in the intracellular compartments. These molecules detect infection-derived ligands through their extracellular/luminar domain known as leucine-rich repeats (LRRs) and signal through their cytosolic conserved region known as toll-like/interleukin-1 receptor (TIR) homology domain to trigger the downstream signaling adaptor proteins such as myeloid differentiation primary response gene 88 (MyD88) [3].

TLRs are expressed on a variety of cells, including innate immune system cells such as macrophages, neutrophils, dendritic cells (DCs), natural killer (NK) cells, and mast cells, as well as the adaptive immune system ( $\mathrm{T}$ and B lymphocytes), stromal cells, and different types of tumor cells [4]. The wide 
expression and functional role of TLRs in the tumorinfiltrating immune cells and the intrinsic role of these cell types in cancer progression or anticancer immune response highlight the potential of TLR as a promising target for cancer immunotherapy. Therefore, pharmacological compounds that can activate TLR molecules have been extensively studied for boosting the immune response against malignant cells. As we discuss in the next sections, this strategy not only activates intrinsic immune cells but also can benefit adoptively transferred immune cells in cell-based immunotherapy settings. Moreover, since TLRs are potent stimulatory molecules in many immune cells, their signaling domains can be applied for engineering synthetic molecules such as CARs for genetic modification of therapeutic immune cells. In this review, we first discuss the role of TLRs in the immune microenvironment of cancer to provide a background on the roles played by TLRs in the cancer microenvironment. Then, we will survey current reports on the application of TLR modulators in cancer immunotherapy and the TLR-based strategies for boosting immune cell therapies of cancer.

\section{TLRs in Cancer Immunity}

2.1. Dendritic Cells. Although the frequency of DCs in the tumor microenvironment is low, they are very important to orchestrate antitumor response in the tumor microenvironment [5]. It is demonstrated that maturation of murine DCs directed by TLR stimulation primes antigen presentation and is pivotal for induction of T cell cytotoxicity. Signaling via activated TLR3 and TLR7 exerts maturation of DC subpopulations and enhances DC-directed immunogenicity mainly via IL-27-mediated signaling $[6,7]$. Notably, activation of TLR3 on human breast cancer-associated dendritic cells has been shown to increase IFN- $\lambda$ production which in turn directed IL-12 release. This IFN-directed phenotype provided a Th1 microenvironment and enhanced cytotoxic T cell activation [8]. Activation of TLR4 has been shown to enhance DC maturation which promoted anticolorectal cancer T cell response in vitro [9]. Similarly, stimulation of DCs via TLR-4 activation and tumor antigens significantly increased cytotoxic CD8+IFN $\gamma+\mathrm{T}$ cells in vivo [10]. Stimulation of TLR7/8 on dendritic cells isolated from leukemic blasts of AML patients has been shown to promote efficient maturation and subsequently activate autologous cytotoxic T cells in vitro. Furthermore, targeting TLR7/8 was a crucial addition to TLR3, 2, or 4 activations to prime DC maturation and production of IL-12 [11].

Moreover, activation of plasmacytoid dendritic cells via TLR7 signaling interestingly resulted in murine melanoma cell killing. TLR7 enabled tumor-associated effector pDCs to educate NK cells, mDCs, as well as activation of CD8+ T cells [12]. A similar trend was also observed on ALL patients. pDC activation via TLR9 molecules directed IFN production which in turn activated NK cells by engagement of TRAIL and CD69 expression [13]. This antitumor TLR7 effect was also shown in CNS tumors which increased DC maturation and tumorspecific CD8+ T cells in mice [14]. Activation of DCs via TLR3 and TLR7/8 activated CD8+ $\mathrm{T}$ cell response and improved therapeutic activity of DC-targeted vaccines [15].
2.2. Macrophages. Macrophages are important immune cells functioning as tumor-protective subtype M1 or tumorpromoting M2 subtypes. It is well evident that skewing M2 subtypes in the tumor microenvironment to M1 can enhance antitumor properties of M1 macrophages [16]. Studies demonstrated the role of TLR3 activation to revert M2 phenotype to M1 mainly via recruiting IFN signaling cascade in vitro and in vivo. The latter resulted in the expression of costimulatory molecules such as CD80, CD86, and CD40 as well as immunostimulatory cytokines IL-6, IL-12, and TNF- $\alpha$. Consequently, this resulted in improved antigen uptake by macrophages and become capable of activating $\mathrm{T}$ cells which augmented immune control of tumor growth in mice [17]. A similar result was obtained against Lewis lung carcinoma cancer cells in mice via TLR3 activation as well as TLR4 engagement in sarcoma-bearing mice $[18,19]$. It has shown that TLR4 may have effects on macrophage migration via NF- $\kappa \mathrm{B}, \mathrm{TNF}-\alpha$, and VEGF expression [20]. In another study, antitumor crosstalk between macrophages and NK cells via engagement of TLRs was shown ex vivo. This TLR-directed M1 antitumor phenotype was accompanied by the production of immunostimulatory cytokines such as IL-18 from human ovarian tumors and stimulated resting NK cells to produce IFN $\gamma$ and Th1-type immune responses [21].

Furthermore, it is well documented that myeloid-derived suppressor cell (MDSC) differentiation to either M1 or M2 macrophages is possible in tumor environment which can exert antitumor or protumor effects, respectively [22, 23]. TLR7/8 activation has been shown to differentiate MDSCs in the tumor microenvironment towards M1 phenotype and enhance tumor regression in mice. This TLR-directed antitumor activity synergistically decreased oxaliplatin resistance in mice harboring colorectal cancer [24]. The role of TLR2/6 stimulation on macrophages to derive NK cell activation and $\mathrm{T}$ cell cytotoxicity was also reported in several tumors such as pancreatic cancer as well as metastasis mice models $[25,26]$. This NF- $\kappa \mathrm{B}$-directed signaling increases COX-2 expression on macrophages and monocytes to derive immune surveillance in tumors [25].

2.3. Tumor Cells. TLR8-mediated signaling in tumor cells reversed immune suppression in the tumor microenvironment via blocking cAMP production. This helped overcome naïve/effector $\mathrm{T}$ cell senescence in the immunosuppressive microenvironment of tumor cells [27]. Crosstalk between tumor cells and $\gamma \delta$ T cells via TLR2 and TLR7 signaling has been reported. TLR2 and 7 activations directed CD54 expression in pancreatic adenocarcinoma and lung and head and neck carcinomas which significantly directed effector function of T cells in vitro [28]. TLR7 activation of tumor cell lines such as Hela S3, keratinocytes, and fibroblasts directly promoted tumor cell apoptosis [29]. Moreover, this antiapoptosis effect TLR7 activation can be directed via infiltrated cytotoxic lymphocytes (CTL), NK, and DCs in the tumor microenvironment. Activation of TLR3-promoted apoptosis of prostate cancer cells via PKC-alpha-dependent signaling in combinational therapy with 5-FU significantly increased apoptosis of human colon cancer cells [30, 31]. The direct antitumor effect of TLR5 activation has been reported in 
mouse xenografts of human breast cancer cells [32]. The same autocrine effect of TLR5 activation was also reported on glioma cells via NF-kappaB activation and NO production [33].

2.4. B Cells. B cells express a variety of TLRs which can transmit strong activation signals that synergize with B cell receptor signaling [34]. The role of TLR7, as well as TLR8, on enhancing B cell antibody and cytokine production is well documented. These activated B cells which are similar to CD40-activated B cells showed increased survival and upregulation of B7 costimulatory molecules [35]. Stimulation of TLR1/2, TLR7, and TLR9 in B cells induces the secretion of a wide range of cytokines and chemokines [36]. Increased expression of costimulatory molecules, enhanced cytokine production, and more efficient antigen presentation by $\mathrm{B}$ cells can consequently result in better activation of the helper T cells [34]. There are also several reports demonstrating that TLR stimulation promotes effector functions of B cells including proliferation, antibody production, and Ig class switching [37-39].

2.5. NK Cells. NK cells are a type of lymphocyte that functions as a first-line defense against tumor cells. It is well documented that almost all TLRs can be expressed on NK cells depending on the NK cell population. Among all, signaling via TLR3, 7, 8, and 9 had been shown as a crucial route in tumor biology. Activation of TLR3 which is highly expressed on human NK cell lines such as NK92, YTC12, and YTS resulted in enhanced cytotoxicity effects on K562 cells. Moreover, targeting TLR3 enabled NK cells to kill head and neck squamous cell carcinoma (HNSCC) by secreting IFN $\gamma$ [40, 41]. Activation of nucleic acid-sensing TLRs such as TLR7, 8 , and 9 has been reported to enable the antitumor activity of NK cells. Activation of these TLRs is highly dependent on other cells in the tumor microenvironment. Although the expression of TLR7/8 on NK cells is controversial [42, 43], some reports showed that stimulation of TLR7/8 expression on NK cells via cytokines released from other cells activates NK cells and promotes their proliferation. Secretion of IFN $\gamma$ and IL-12 and other inflammatory cytokines via TLR7/8 stimulation enabled NK cells to kill HNSCC and melanoma B16 tumor cells while TLR9 triggered cytotoxic activity of these cells on melanoma cells [44-46]. It was also reported that activation of NK cells via TLR2 could accelerate the antitumor activity of HER2-targeted monoclonal antibody therapy in vitro and in vivo [47].

2.6. Effector T Cells. Certain TLRs are expressed on different types of $\mathrm{T}$ cells which can directly modulate $\mathrm{T}$ cell function and antitumor activity of these cells. TLR1/2, 5, and 7/8 activation has been reported to stimulate proliferation and cytokine production of memory CD4+ T cells. For instance, increased secretion of IFN $\gamma$ and a slight increase in IL6 from freshly isolated $\gamma \delta$ T cells have been reported via TLR2 and TLR3 stimulations. A high concentration of TLR5 ligand increased CD4+ $\mathrm{T}$ cell proliferation and IL2 expression [48]. Activation of several TLRs such as TLR2, 3, and 9 in purified $\mathrm{B} 6 \mathrm{CD} 4+\mathrm{T}$ cells can act as a costimulatory signal for TCR activation [49]. TLR9 activation via NF- $\kappa$ B signaling inhibits apoptosis in CD4+ T cells; similarly, signaling via activation of TLR2 stimulated CD8+ T cell survival [50]. TLR7 and TLR8 activation of CD4+ T cells helped proliferation and enhanced production of IFN $\gamma$, IL-2, and IL-10 [51]. Moreover, activation of TLR7 induced effector activity of $\mathrm{CD} 8+\mathrm{T}$ cells via the MyD88 and AKT-mTOR pathway which is strongly dependent on glucose uptake in vitro [52]. Although as mentioned earlier, activation of DCs, NK cells, and Tregs can modulate CD8+ T cell function, it is well documented that different TLRs can directly modulate different properties of CD8+ T cells in the tumor microenvironment. TLR1/2 activation is believed to entail effector activity to CD8+ T cells. Granzyme B, perforin, TNF- $\alpha$, and IFN $\gamma$ production is augmented via TLR1/2 activation both in vivo and in vitro. Ligation of TLR1/2 on CTLs could generate antitumor activity against B16 melanoma cells and result in significant tumor reduction [53]. This enhanced CTL cytotoxicity is suggested to be at least partly via the mTOR pathway. Inhibition of mTOR, Akt, and PKC in T cells hindered cytotoxic activity of CD8 $\mathrm{T}$ cells dramatically [54]. It is reported that TLR3 activation can also modulate effector CD8+ T cell function and increase IFN $\gamma$ production as a functional coreceptor [55]. Moreover, direct activation of CD8+ T cells via engaging TLR3 is reported in an in vitro assay using transgenic OT-1 (CD8+) T cells. This antigen-independent stimulation of CD8+ T cells was followed by robust expansion and increased expression of activation markers in vivo [56].

2.7. Regulatory $T$ Cells. It is well documented that specific TLRs can modulate the suppressive activity of murine and human regulatory T cells (Tregs). Activation of TLR4 on Treg improved their survival and enhanced their suppressive activity. Besides, TLR5 activation in a low concentration of ligand increased Foxp3 expression and slightly enhanced suppressive activity of human CD4+CD25+ Treg [48]. In contrast, TLR8 activation of Tregs via TLR8-MyD88IRAK4 signaling could significantly revert the suppressive function of these cells in a tumor-bearing mouse model [57]. The effect of TLR2 activation to promote Treg proliferation was shown in several experiments although its effect on reverting suppressive activity of these cells is controversial $[58,59]$. For example, TLR2 activation was reported to directly promote proliferation of Tregs in vivo; however, it inhibits immunosuppressive activity [60]. Since the overall effects of most TLR agonists are towards the enhancement of antitumor effects (see next section), one can speculate that TLR-mediated stimulation of Tregs is not a major challenge for TLR-based immunotherapy. However, more precise investigations are required to address the underlying mechanisms that orchestrate immune cell interactions during systemic TLR stimulation.

\section{TLR Agonists for Cancer Immunotherapy}

Given the current knowledge on TLR and their ligands, various types of TLR agonists are developed including natural microbial components or synthetic ones and being used in anticancer therapy. These agents are considered immune- 
stimulating factors which enhance TLR signaling and activate an innate immune response that results in long-lasting adaptive immunity. The TLR agonists have been used for a variety of clinical applications. These agents could be used as vaccine adjuvants which caused strong TH1 and CTL response [61]. The MPLA is a TLR agonist that enhances immunity in hepatitis B vaccines [62]. The CpG ODN is also used in various vaccines such as hepatitis $B$, hepatitis $C$, and influenza which unlike complete Freund's adjuvant does not initiate local inflammatory reaction [63]. Another application of TLR agonist is for the treatment of allergic diseases with TLR agonists that enhance TH1 response, inhibiting TH2 development and related cytokines such as IL-4, IL-5, and IL-10 [64]. VTX-1463 (a TLR4 agonist) could reduce clinical symptoms in ragweed-allergic patients [65]. Treatment of infectious diseases is another application of TLR agonists. These molecules could enhance the specific immune response against microbial infections.

TLR agonists have been extensively studied for the enhancement of the immune response against cancer. These molecules could stimulate cytotoxic lymphocytes, natural killer cells (NK cells), and dendritic cells (DCs) which could be important characteristics in cancer therapy either in monotherapy or combined modal strategies. These agents are also used as vaccine adjuvants in humans to increase the immune response [66]. Although TLR agonists are generally considered potential anticancer agents, it should be noticed that the efficacy of some TLR antagonists may be dependent on the cancer type and the context of the immune system [67].

There are several examples of TLR agonists studied for boosting anticancer immune response. TLR2 agonists Pam3Cys (synthetic triacylated lipoproteins), SMP-105 (cell wall skeleton components), have been used for bladder cancer [68]. TLR3 stimulator poly I:C (a synthetic analog of viral dsRNA) increased production of type I IFNs and inhibited tumor cell proliferation [69], and ARNAX (DNA-capped dsRNA modulator, TLR3 agonist) increased CTL and memory cell numbers [70]. Multiple TLR4 activators have been studied in experimental and clinical trials, including AS04 (FDA-approved for cervical cancer), MPLA (derivative of lipid A, cervical cancer), and GLA-SE (G100-synthetic GLA, lymphoma tumor) [71, 72]. CBLB502 (natural flagellin/entolimod) and M-VM3 (Mobilan, a recombinant nonreplicating adenovirus encoding flagellin) are some of the TLR5 agonists which have been studied for head and neck cancer and prostate cancer, respectively $[73,74]$. Imiquimod (a TLR7 agonist) is used for cervical, vaginal, and vulvar intraepithelial cancers [75]. Some of the important examples of TLR9 agonists are CpG-7909 (single-stranded CpG ODN, non-Hodgkin's lymphoma, renal cell carcinoma, melanoma, cutaneous $\mathrm{T}$ cell lymphoma and glioblastoma, and nonsmall-cell lung cancer), IMO2055 (CpG ODN-based oligonucleotide, advanced NSCLC), MGN1703 (natural DNA molecule, advanced solid tumors, small cell lung cancer), dSLIM (two single-stranded loops connected with doublestranded stem, metastatic colorectal cancer), SD-101 (follicular lymphoma), KSK-CpG (phosphorothioated CpG ODN, melanoma), ODN M362 (hepatocarcinoma), and CpG-
1826 (enhance anticancer effect in glioma xenograft model) [68, 76-90].

A list of TLR agonists which are mentioned above is summarized in Table 1 (see also Figure 1). Although there may be more established or candidate TLR agonists under different phases of preclinical and clinical studies, they follow more or less similar biological strategies to induce TLR signaling. Another strategy is to combine TLR agonists with other immunotherapy agents to obtain a synergistic effect. For instance, combining TLR7 and TLR9 agonists (1V270 and SD-101) with anti-PD1 checkpoint inhibitor activated tumor-infiltrated macrophages and induced a potent antitumor immune response, preventing primary tumor growth and metastasis in a mouse model of head and neck cancer [91]. Similar enhancement in the immune response was obtained by combining the agonists of TLR9 (ODN1826 or MGN1703) with CTLA-4 or PD-1 blockade in a mouse model of poorly immunogenic melanoma [92]. It is noteworthy that some TLR antagonists including small molecules, interfering RNAs, and antibodies also have been used for cancer therapy. However, the rationale behind the application of these TLR inhibitors is to target protumor TLRs expressed on the malignant cells and not the immune cells. One of the challenges with these antagonists is that they cannot target TLRs specifically on the tumor cells and may cause unfavorable effects on the immune microenvironment of cancer. We do not cover this approach here since it is not considered immunotherapy; thus, it is out of the scope of this review and has been reviewed elsewhere [93].

\section{TLR-Based Strategies in Immune Cell-Based Therapy of Cancer}

Several types of immune cells including T cells, NK cells, DCs, and macrophages have been used for cancer immunotherapy, as reviewed elsewhere [116-119]. Since TLRs are involved in the regulation of these immune cells, it is plausible that manipulation of TLRs modifies and improves these cell-based immunotherapy methods. To exploit TLR-based regulation for enhancing transferred cell-based immunotherapy, two general strategies are conceivable: first, to utilize TLR or their derivative domains for genetic modification of the immune cells to augment their functionality against the malignant cells; second, to administrate a TLR agonist or antagonist along with the immune cells to provide them with inflammatory and costimulatory signals. In this section, we will discuss current progress in these approaches and possible future opportunities.

Genetic modification of immune cells provides a valuable means for directing their function towards the tumor cells and arms them with transgenes that confer resistance against the harsh immunosuppressive microenvironment of the tumor. For instance, genetic modification of $\mathrm{T}$ cells by CARs enables them to recognize and kill the tumor cells via surface antigens [120]. CAR molecule is an engineered transmembrane protein that can recognize a specific antigen by its extracellular domain, typically a single-chain fragment variable (scFV), and transmit activation signals through its cytosolic domains [121]. Signals transmitted by the cytosolic 
TABLE 1: A summary of TLR agonists with their corresponding TLR targets.

\begin{tabular}{lccc}
\hline Target TLR & Agonist & Molecule type & References \\
\hline & Pam3Cys & Lipoproteins & {$[94]$} \\
TLR2 & SMP-105 & Cell wall skeleton components & {$[95,96]$} \\
& CBLB612 & Lipopeptide & {$[97]$} \\
& Poly I:C & & {$[98]$} \\
& Poly-ICLC & & {$[99]$} \\
TLR3 & Poly-IC12U & Synthetic dsRNA & {$[100]$} \\
& IPH 3102 & & {$[101]$} \\
& ARNAX & & {$[102,103]$} \\
& MPLA & Lipid & {$[104]$} \\
TLR4 & GLA-SE & Lipid & {$[105]$} \\
& AS04 & MPL and aluminum hydroxide & {$[106]$} \\
& OK-432 & Protein & {$[107]$} \\
TLR5 & CBLB502 & A virulence Streptococcus pyogenes strain & {$[61]$} \\
TLR7 & M-VM3 & Adenoviral vector & {$[74]$} \\
TLR8 & Bistriazolyl & Small molecule & {$[108]$} \\
& VTX1463 & Small molecule & {$[109]$} \\
& MGN1703 & Polynucleotide & {$[61]$} \\
& CpG-7909 & & {$[110]$} \\
TLR9 & IMO2055 & & {$[111]$} \\
& dSLIM & & {$[61]$} \\
& SD-101 & & {$[112,113]$} \\
& KSK-CpG & & {$[88]$} \\
& ODN M362 & & {$[114]$} \\
& CpG-1826 & & {$[115]$} \\
\hline
\end{tabular}

domains play a crucial role in regulating different aspects of cytotoxicity, memory formation, and persistence of CAR T cells [122]. First-generation CARs harboring only a CD3 $\zeta$ signaling domain proved inferior to the second-generation CARs which contain an additional signaling domain from a costimulatory receptor such as CD28 (Figures 2(a) and 2(b)) [123]. Since TLRs provide potent costimulatory signals for $\mathrm{T}$ cell activation, their intracellular domains also can be used for the construction of the CAR molecules. Accordingly, a third-generation anti-CD19 CAR containing CD28, CD3 $\zeta$, and TLR2 signaling domains (1928zT2) revealed the synergistic effect between TLR2 and CD28 costimulatory signals (Figure 2(c)) [124]. A recent study shows that tethering a TLR adaptor molecule, MyD88, along with a CD40 signaling domain to the cytosolic domain of a first-generation CAR construct promotes CAR T cell survival, proliferation, and antitumor activity (Figure 2(d)) [125]. The same MyD88CD40 fusion protein when linked to a rimiducid-binding domain (FKBP12v36) forms an inducible switch molecule that can enhance in vivo expansion and persistence of CAR $\mathrm{T}$ cells upon systemic administration of the small molecule rimiducid (Figure 2(e)) [126]. Previous studies have shown that signaling through different costimulatory domains results in distinct functional characteristics in CAR $\mathrm{T}$ cells in terms of memory differentiation, persistence, and toxic side effects $[122,127]$, implying that the selection of the costimulatory domain can be applied to fine-tune CAR T cell function. Therefore, the aforementioned TLR-derived costimulatory domains can expand the signaling domain arsenal to further customize CAR architecture and function.

Besides T cells, TLR signaling components have also been used in the context of other immune cells that can also be genetically engineered by specific variants of CARs. For instance, the aforementioned rimiducid-inducible molecular switch composed of MyD88, CD40, and FKBP12v36 domains (Figure 2(e)) has been used in NK cells genetically modified with CAR and IL-15, resulting in the robust proliferation and prolonged persistence in vivo [128]. Another example of the application of TLR-derived domains for genetic engineering of the immune cells comes from CARmodified macrophages. Macrophages genetically modified to express CAR molecule consisting of an extracellular scFV domain and a cytosolic TIR domain are reported to show antigen-specific cytotoxicity and expansion both in vitro and in vivo $[129,130]$. These instances suggest that genetically engineered receptors mimicking TLR stimulation may be used to modify immune cells which naturally express and get stimulated by TLRs.

As mentioned earlier, agonists of different TLRs can trigger the antitumor response by modulating specific types of endogenous immune cells. The same principle can be applied for upregulating the adoptively transferred immune cells. For instance, poly I:C (a TLR3 ligand) treatment has been shown to synergize with an antiepidermal growth factor receptor 


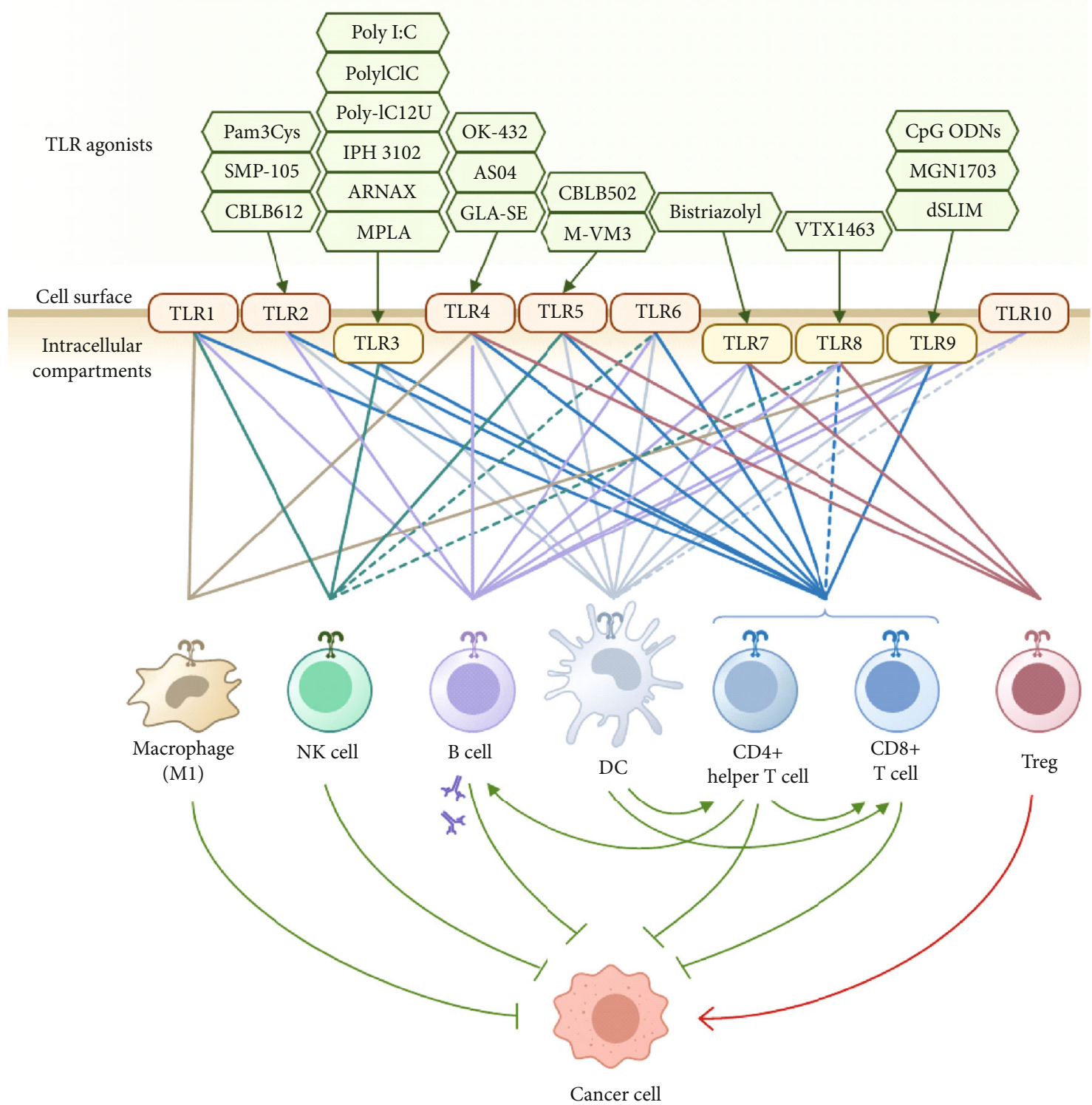

FIgURE 1: Targeting TLRs expressed on the immune cells in the tumor microenvironment with TLR agonists. Examples of TLR agonists are shown at the top. TLRs which are expressed in human cell surface or intracellular compartments are shown in the middle. The expression of each TLR on different immune cell types is indicated by color-coded lines. Some reported low-level expressions of TLRs with unknown functional status are ignored in this figure.

variant III (EGFRvIII) CAR T cell therapy in immunocompetent xenograft models of colon and breast cancer [131]. In this setting, poly I:C mediated its effect through type I IFNs and downregulation of immunosuppressive myeloidderived suppressor cells (MDSCs). TLR agonists have also been used for ex vivo activation of the immune cells before being transferred for cancer therapy. For example, coculture of NK cells and DCs in the presence of lipopolysaccharide, which is TLR4 agonist, resulted in superior DC maturation with potent antitumor activity when transferred to a mouse colon cancer model [132]. This approach can be extended to other immune cell therapies and various TLR agonists and antagonists, considering the compelling data on the effect of the TLR modulators on the antitumor effects of $\mathrm{T}$ cells [133], NK cells [134], DCs [135], and macrophages [136].

\section{Recent Clinical Trials on TLR-Based Cancer Immunotherapy}

TLR agonists have been under clinical investigation for years and in several cases showed potential therapeutic efficacy against cancers. The US Food and Drug Administration (FDA) has approved several TLR agonists for cancer treatment, such as BCG (a primarily TLR2/4 agonist) for bladder noninvasive transitional cell carcinoma, AS04 (a TLR4 agonist) for cervical cancer, and imiquimod (a TLR7 agonist) for superficial basal cell carcinoma [137]. More recent published results on clinical investigation of TLR agonists in cancer (Table 2) showed the benefit of these molecules when combined with another immunotherapy agent. For example, combining peptide or recombinant cancer vaccines with 


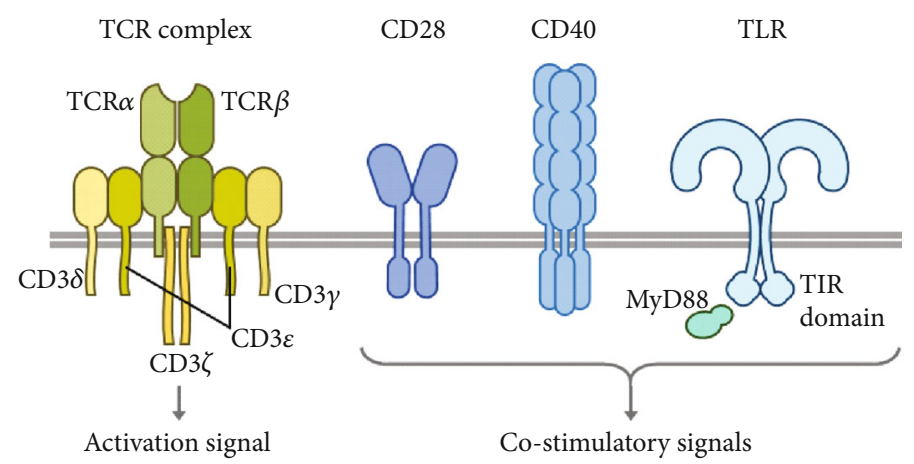

(a)

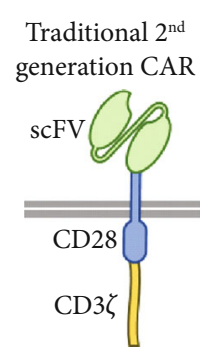

(b)

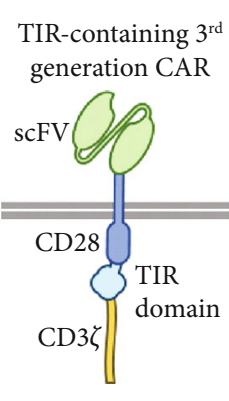

(c)

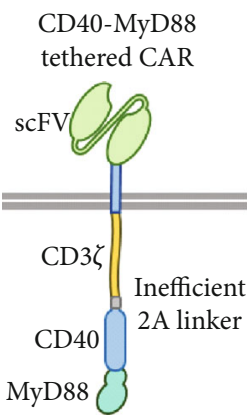

(d)

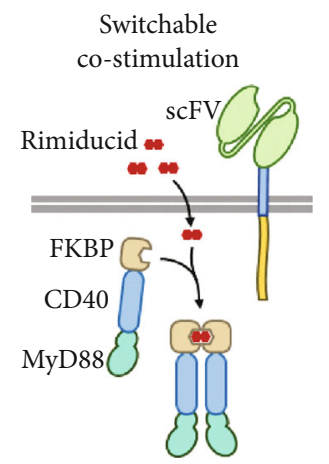

(e)

FIgURE 2: TLR-based strategies for improvement of CAR T cells. (a) Schematic presentation of wild-type T cell proteins from which signaling domains are derived to construct chimeric synthetic receptors. (b) Traditional second-generation CAR containing an scFV domain for antigen recognition on the extracellular portion and $\mathrm{CD} 3 \zeta$ and costimulatory signaling domains on the cytosolic side $(\mathrm{CD} 28$ domain is shown here as an example). (c) A third-generation CAR with a TIR signaling domain derived from TLRs. (d) A CD40-MyD88 fusion protein tethered to a first-generation CAR through an inefficient 2A linker. (e) The CD40-MyD88 fusion is linked to a rimiducid-binding domain from an FKBP protein to form a pharmacological switch that can transmit a costimulatory signal by dimerization upon rimiducid treatment.

agonists of TLR3, 4, and 9 showed improved immune stimulation and enhanced $\mathrm{T}$ cell response in melanoma patients $[99,138,139]$. The addition of TLR8 agonist Motolimod (VTX-2337) improved the cellular antitumor immune response induced by an anti-EGFR antibody (cetuximab) in head and neck squamous cell carcinoma $[140,141]$. One report described the simultaneous administration of cellbased immunotherapy with a TLR3 agonist, where treatment with peptide-pulsed DCs plus poly-ICLC was tolerated and induced a detectable tumor-specific $\mathrm{T}$ cell response in patients with pancreatic cancer [142]. However, the addition of TLR2 agonist CADI-05 to chemotherapy with cisplatinpaclitaxel did not provide any survival benefit for nonsmall-cell lung cancer patients in a phase II clinical trial [143]. Another study that combined paclitaxel chemotherapy with a TLR7 agonist (imiquimod) showed a short-lived improvement in disease regression [144].

Trends of the ongoing clinical trials also suggest that combinatorial strategies are being pursued in the field of TLR agonists. A summary of ongoing clinical trials started between 2019 and April 2021 is provided in Table 3. Clinical trials started before this period are reviewed elsewhere [137]. Most of these recently started studies are on a combination of TLR inhibitors with another immunotherapy agent including PD-1 blockers, CTLA- 4 blockers, and agonistic anti-OX40 antibodies. This is in line with recent preclinical findings that also suggest that this kind of combination may produce a synergistic effect to evoke a more effective immune response $[91,92]$.

\section{Conclusion}

TLRs are present on multiple immune cells within the tumor microenvironment. Given the important role of these receptors on the regulation of immune response, they are considered to be promising targets for modulation of the immune system towards a potent antitumor response. Recent data on the application of TLR agonists in experimental and clinical settings demonstrate the potential of this strategy for cancer treatment. Although current studies have shown the proof of concept for the application of TLR-targeted drugs for cancer treatment, given the variations in tumor immunophenotypes, it is likely that cancer type and microenvironment condition among other factors may affect the clinical outcome of TLR-targeting immunotherapies. These differences need to be addressed especially when preclinical animal experiments are conducted. More recent data suggest that combining TLR antagonists with other immunotherapy approaches, such as checkpoint inhibitors and cell-based immunotherapy, could boost the efficacy of immunotherapy 
TABLE 2: Clinical studies on the application of TLR agonists for cancer treatment published since 2016.

\begin{tabular}{|c|c|c|c|c|c|c|}
\hline $\begin{array}{l}\text { Target } \\
\text { TLR }\end{array}$ & $\begin{array}{c}\text { TLR } \\
\text { agonist }\end{array}$ & Companion treatment & Conditions & Phase & Results & Reference \\
\hline TLR2 & CADI-05 & $\begin{array}{c}\text { Chemotherapy } \\
\text { (cisplatin-paclitaxel) }\end{array}$ & $\begin{array}{l}\text { Non-small-cell } \\
\text { lung cancer }\end{array}$ & II & $\begin{array}{l}\text { No survival benefit was observed with the addition } \\
\text { of CADI-05 to chemotherapy. }\end{array}$ & {$[143]$} \\
\hline \multirow{2}{*}{ TLR3 } & \multirow{2}{*}{ Poly-ICLC } & $\begin{array}{l}\text { NY-ESO-1 peptide } \\
\text { vaccine }\end{array}$ & Melanoma & $\mathrm{I} / \mathrm{II}$ & Enhanced specific CD8+ T cell response. & {$[138]$} \\
\hline & & Peptide-pulsed DCs & Pancreatic cancer & I & $\begin{array}{l}\text { The treatment was safe and induced a measurable } \\
\text { tumor-specific T cell population. }\end{array}$ & {$[142]$} \\
\hline $\begin{array}{l}\text { TLR3, } \\
\text { TLR4 }\end{array}$ & $\begin{array}{l}\text { Poly-ICLC, } \\
\text { LPS }\end{array}$ & $\begin{array}{l}\text { Multipeptide vaccine } \\
\text { and incomplete } \\
\text { Freund's adjuvant }\end{array}$ & Melanoma & I & $\begin{array}{l}\text { Combinations of poly-ICLC or LPS with peptide } \\
\text { vaccine and incomplete Freund's adjuvant are safe } \\
\text { and induce T cell response. }\end{array}$ & [99] \\
\hline $\begin{array}{l}\text { TLR4 } \\
\text { TLR9 }\end{array}$ & AS15 & $\begin{array}{l}\text { Recombinant MAGE- } \\
\text { A3 vaccine }\end{array}$ & Melanoma & I & $\begin{array}{l}\text { The treatment was tolerated and produced durable } \\
\qquad \mathrm{Ab} \text { responses. }\end{array}$ & [139] \\
\hline TLR7 & Imiquimod & $\begin{array}{l}\text { Chemotherapy } \\
\text { (paclitaxel) }\end{array}$ & $\begin{array}{l}\text { Breast cancer } \\
\text { cutaneous } \\
\text { metastases }\end{array}$ & II & $\begin{array}{l}\text { The combination was effective in inducing disease } \\
\text { regression, but responses were short-lived. }\end{array}$ & {$[144]$} \\
\hline TLR8 & Motolimod & $\begin{array}{l}\text { Anti-EGFR } \\
\text { (cetuximab) }\end{array}$ & $\begin{array}{l}\text { Head and neck } \\
\text { squamous cell } \\
\text { carcinoma }\end{array}$ & I & $\begin{array}{l}\text { The addition of TLR agonist enhanced the cellular } \\
\text { antitumor immune response. }\end{array}$ & $\begin{array}{c}{[140,} \\
141]\end{array}$ \\
\hline TLR9 & GNKG168 & N/A & $\begin{array}{l}\text { Minimal residual } \\
\text { disease positive } \\
\text { acute leukemia }\end{array}$ & I & Immunologic changes were observed. & {$[145]$} \\
\hline
\end{tabular}

TABLE 3: A summary of recent ongoing clinical trials on TLR agonists started after 2019.

\begin{tabular}{|c|c|c|c|c|c|c|}
\hline Target TLR & TLR agonist & Companion treatment & Conditions* & Phase & Status & NCT number \\
\hline TLR2/4 & $\begin{array}{l}\text { BCG, PPD, } \\
\text { Typhim Vi }\end{array}$ & $\begin{array}{l}\text { Chemotherapy, radiofrequency } \\
\text { ablation }\end{array}$ & Colorectal cancer & I & Not yet recruiting & NCT04062721 \\
\hline \multirow{2}{*}{ TLR3 } & Poly-ICLC & Peptide vaccine, anti-CD40 & Melanoma & $\mathrm{I} / \mathrm{II}$ & Recruiting & NCT04364230 \\
\hline & Rintatolimod & Anti-PD-1, chemotherapy & Ovarian cancer recurrent & $\mathrm{I} / \mathrm{II}$ & Recruiting & NCT03734692 \\
\hline \multirow[b]{2}{*}{ TLR4 } & \multirow[b]{2}{*}{ GLA-SE } & N/A & Lymphoma, T cell, cutaneous & II & Withdrawn & NCT03742804 \\
\hline & & $\begin{array}{l}\text { Anti-CTLA-4, anti-PD-1, } \\
\text { chemotherapy }\end{array}$ & Colorectal cancer metastatic & I & Withdrawn & NCT03982121 \\
\hline \multirow{4}{*}{ TLR7 } & BNT411 & Anti-PDL-1, chemotherapy & Solid tumor, lung cancer & $\mathrm{I} / \mathrm{II}$ & Recruiting & NCT04101357 \\
\hline & Imiquimod & $\begin{array}{l}\text { Anti-PD-1, focused ultrasound } \\
\text { ablation }\end{array}$ & Multiple solid tumors & I & Recruiting & NCT04116320 \\
\hline & RO7119929 & Anti-IL-6 receptor & Biliary tract and liver cancer & I & Recruiting & NCT04338685 \\
\hline & SHR2150 & $\begin{array}{l}\text { Chemotherapy, anti-PD-1, } \\
\text { anti-CD } 47\end{array}$ & Solid tumor & $\mathrm{I} / \mathrm{II}$ & Recruiting & NCT04588324 \\
\hline TLR7/8 & TransCon & Anti-PD-1 & Solid tumors & $\mathrm{I} / \mathrm{II}$ & Recruiting & NCT04799054 \\
\hline TLR8 & Motolimod & Anti-PD-1 & Carcinoma, squamous cell & I & Recruiting & NCT03906526 \\
\hline \multirow{5}{*}{ TLR9 } & \multirow{2}{*}{ CMP-001 } & Anti-OX40 & $\begin{array}{c}\text { Pancreatic cancer, unresectable } \\
\text { solid neoplasm }\end{array}$ & I/II & Not yet recruiting & NCT04387071 \\
\hline & & Anti-PD-1 & Melanoma & II & Recruiting & $\begin{array}{l}\text { NCT04708418 } \\
\text { NCT04401995 }\end{array}$ \\
\hline & \multirow{2}{*}{ SD-101 } & Radiation therapy, anti-PD-1 & Pancreatic cancer & I & Recruiting & NCT04050085 \\
\hline & & Anti-OX40 & Malignant solid neoplasm & I & Recruiting & NCT03831295 \\
\hline & Tilsotolimod & Anti-CTLA-4, anti-PD-1 & Advanced cancer & I & Recruiting & NCT04270864 \\
\hline
\end{tabular}

${ }^{*}$ Indicated conditions are summarized in this table. Complete information is available via the provided ClinicalTrials.gov identifier (NCT number).

regimens $[91,131]$. The trend of recent clinical trials also suggests that combinatorial therapy containing a TLR agonist as a booster for immune response is considered as a more promising approach by the investigators (Tables 2 and 3).
As discussed above, the application of TLR-based genetic engineering strategies may also provide new options for cancer immunotherapy. Since previous experiences with other costimulatory domains showed the impact of the domain 
architecture of engineered systems on the clinical outcome, it is necessary for future studies to make a head-to-head comparison between TLR-containing engineered receptors with other synthetic structures in preclinical and clinical settings to elucidate the characteristics of TLR-derived signals in the engineered immune cell therapies and its impact in the clinical outcome.

\section{Conflicts of Interest}

The authors declare that there is no conflict of interest regarding the publication of this paper.

\section{References}

[1] A. Ribas and J. D. Wolchok, "Cancer immunotherapy using checkpoint blockade,” Science, vol. 359, no. 6382, pp. 1350$1355,2018$.

[2] D. Han, Z. Xu, Y. Zhuang, Z. Ye, and Q. Qian, "Current progress in CAR-T cell therapy for hematological malignancies," Journal of Cancer, vol. 12, no. 2, pp. 326-334, 2021.

[3] K. H. Lim and L. M. Staudt, "Toll-like receptor signaling," Cold Spring Harbor Perspectives in Biology, vol. 5, no. 1, p. a011247, 2013.

[4] L. Huang, H. Xu, and G. Peng, "TLR-mediated metabolic reprogramming in the tumor microenvironment: potential novel strategies for cancer immunotherapy," Cellular \& Molecular Immunology, vol. 15, no. 5, pp. 428-437, 2018.

[5] L. Amon, L. Hatscher, L. Heger, D. Dudziak, and C. H. K. Lehmann, "Harnessing the complete repertoire of conventional dendritic cell functions for cancer immunotherapy," Pharmaceutics, vol. 12, no. 7, p. 663, 2020.

[6] A. N. Desch, S. L. Gibbings, E. T. Clambey et al., "Dendritic cell subsets require cis-activation for cytotoxic CD8 T-cell induction," Nature Communications, vol. 5, no. 1, 2014.

[7] A. Pantel, A. Teixeira, E. Haddad, E. G. Wood, R. M. Steinman, and M. P. Longhi, "Direct type I IFN but not MDA5/TLR3 activation of dendritic cells is required for maturation and metabolic shift to glycolysis after poly IC stimulation," PLoS Biology, vol. 12, no. 1, article e1001759, 2014.

[8] M. Hubert, E. Gobbini, C. Couillault et al., "IFN-III is selectively produced by $\mathrm{CDC} 1$ and predicts good clinical outcome in breast cancer," Science Immunology, vol. 5, no. 46, p. eaav3942, 2020.

[9] H. Fang, B. Ang, X. Xu et al., "TLR4 is essential for dendritic cell activation and anti-tumor T-cell response enhancement by DAMPs released from chemically stressed cancer cells," Cellular \& Molecular Immunology, vol. 11, no. 2, pp. 150159, 2014.

[10] H. J. Park, G.-Y. Jang, Y. S. Kim et al., "A novel TLR4 binding protein, $40 \mathrm{~S}$ ribosomal protein $\mathrm{S} 3$, has potential utility as an adjuvant in a dendritic cell-based vaccine," Journal for Immunotherapy of Cancer, vol. 7, no. 1, pp. 60-60, 2019.

[11] M. Nourizadeh, F. Masoumi, A. Memarian et al., "In vitro induction of potent tumor-specific cytotoxic T lymphocytes using TLR agonist-activated AML-DC," Targeted Oncology, vol. 9, no. 3, pp. 225-237, 2014.

[12] B. Drobits, M. Holcmann, N. Amberg et al., "Imiquimod clears tumors in mice independent of adaptive immunity by converting pDCs into tumor-killing effector cells," The Jour- nal of Clinical Investigation, vol. 122, no. 2, pp. 575-585, 2012.

[13] M. Lelaidier, Y. Dìaz-Rodriguez, M. Cordeau et al., "TRAILmediated killing of acute lymphoblastic leukemia by plasmacytoid dendritic cell-activated natural killer cells," Oncotarget, vol. 6, no. 30, pp. 29440-29455, 2015.

[14] R. M. Prins, N. Craft, K. W. Bruhn et al., "The TLR-7 agonist, imiquimod, enhances dendritic cell survival and promotes tumor antigen-specific $\mathrm{T}$ cell priming: relation to central nervous system antitumor immunity," Journal of Immunology, vol. 176, no. 1, pp. 157-164, 2006.

[15] V. Ramakrishna, J. P. Vasilakos, J. D. Tario, M. A. Berger, P. K. Wallace, and T. Keler, "Toll-like receptor activation enhances cell-mediated immunity induced by an antibody vaccine targeting human dendritic cells," Journal of Translational Medicine, vol. 5, no. 1, 2007.

[16] A. Sica and A. Mantovani, "Macrophage plasticity and polarization: in vivo veritas," The Journal of Clinical Investigation, vol. 122, no. 3, pp. 787-795, 2012.

[17] A. Vidyarthi, N. Khan, T. Agnihotri et al., “TLR-3 stimulation skews M2 macrophages to M1 through IFN- $\alpha \beta$ signaling and restricts tumor progression," Frontiers in Immunology, vol. 9, p. 1650, 2018.

[18] E. Müller, M. Speth, P. F. Christopoulos et al., "Both type I and type II interferons can activate antitumor M1 macrophages when combined with TLR stimulation," Frontiers in Immunology, vol. 9, 2018.

[19] Z. Huang, Y. Yang, Y. Jiang et al., “Anti-tumor immune responses of tumor-associated macrophages via toll-like receptor 4 triggered by cationic polymers," Biomaterials, vol. 34, no. 3, pp. 746-755, 2013.

[20] C. H. Lee, C. L. Wu, and A. L. Shiau, "Toll-like receptor 4 signaling promotes tumor growth," Journal of Immunotherapy, vol. 33, no. 1, pp. 73-82, 2010.

[21] F. Bellora, R. Castriconi, A. Dondero et al., "TLR activation of tumor-associated macrophages from ovarian cancer patients triggers cytolytic activity of NK cells," European Journal of Immunology, vol. 44, no. 6, pp. 1814-1822, 2014.

[22] M. J. Hamilton, M. Bosiljcic, N. E. LePard et al., "Macrophages are more potent immune suppressors ex vivo than immature myeloid-derived suppressor cells induced by metastatic murine mammary carcinomas," Journal of Immunology, vol. 192, no. 1, pp. 512-522, 2014.

[23] Y. Yin, X. Huang, K. D. Lynn, and P. E. Thorpe, "Phosphatidylserine-targeting antibody induces M1 macrophage polarization and promotes myeloid-derived suppressor cell differentiation," Cancer Immunology Research, vol. 1, no. 4, pp. 256-268, 2013.

[24] Z. Liu, Y. Xie, Y. Xiong et al., "TLR 7/8 agonist reverses oxaliplatin resistance in colorectal cancer via directing the myeloid-derived suppressor cells to tumoricidal M1-macrophages," Cancer Letters, vol. 469, pp. 173-185, 2020.

[25] C. Müller, D. M. Tufa, D. Chatterjee, P. F. Mühlradt, R. E. Schmidt, and R. Jacobs, "The TLR-2/TLR-6 agonist macrophage-activating lipopeptide- 2 augments human NK cell cytotoxicity when PGE2 production by monocytes is inhibited by a COX-2 blocker," Cancer Immunology, Immunotherapy, vol. 64, no. 9, pp. 1175-1184, 2015.

[26] J. Schmidt, T. Welsch, D. Jäger, P. F. Mühlradt, M. W. Büchler, and A. Märten, "Intratumoural injection of the toll-like receptor-2/6 agonist 'macrophage-activating lipopeptide-2' 
in patients with pancreatic carcinoma: a phase I/II trial," British Journal of Cancer, vol. 97, no. 5, pp. 598-604, 2007.

[27] J. Ye, C. Ma, E. C. Hsueh et al., “TLR8 signaling enhances tumor immunity by preventing tumor-induced T-cell senescence," EMBO Molecular Medicine, vol. 6, no. 10, pp. 12941311, 2014.

[28] H. Shojaei, H.-H. Oberg, M. Juricke et al., "Toll-like receptors 3 and 7 agonists enhance tumor cell lysis by human gammadelta T cells," Cancer Research, vol. 69, no. 22, pp. 8710-8717, 2009.

[29] T. Meyer, I. Nindl, T. Schmook, C. Ulrich, W. Sterry, and E. Stockfleth, "Induction of apoptosis by toll-like receptor-7 agonist in tissue cultures," The British Journal of Dermatology, vol. 149, Suppl 66, pp. 9-13, 2003.

[30] A. Paone, D. Starace, R. Galli et al., "Toll-like receptor 3 triggers apoptosis of human prostate cancer cells through a PKCalpha-dependent mechanism," Carcinogenesis, vol. 29, no. 7, pp. 1334-1342, 2008.

[31] M. Taura, R. Fukuda, M. A. Suico et al., "TLR3 induction by anticancer drugs potentiates poly I:C-induced tumor cell apoptosis," Cancer Science, vol. 101, no. 7, pp. 1610-1617, 2010.

[32] Z. Cai, A. Sanchez, Z. Shi, T. Zhang, M. Liu, and D. Zhang, "Activation of toll-like receptor 5 on breast cancer cells by flagellin suppresses cell proliferation and tumor growth," Cancer Research, vol. 71, no. 7, pp. 2466-2475, 2011.

[33] X. Li, D. Liu, X. Liu et al., "CpG ODN107 potentiates radiosensitivity of human glioma cells via TLR9-mediated NF- $\kappa \mathrm{B}$ activation and NO production," Tumour Biology, vol. 33, no. 5, pp. 1607-1618, 2012.

[34] C. M. Buchta and G. A. Bishop, "Toll-like receptors and B cells: functions and mechanisms," Immunologic Research, vol. 59, no. 1-3, pp. 12-22, 2014.

[35] G. A. Bishop, Y. Hsing, B. S. Hostager, S. V. Jalukar, L. M. Ramirez, and M. A. Tomai, "Molecular mechanisms of B lymphocyte activation by the immune response modifier R848," Journal of Immunology, vol. 165, no. 10, pp. 55525557, 2000.

[36] S. Agrawal and S. Gupta, "TLR1/2, TLR7, and TLR9 signals directly activate human peripheral blood naive and memory B cell subsets to produce cytokines, chemokines, and hematopoietic growth factors," Journal of Clinical Immunology, vol. 31, no. 1, pp. 89-98, 2011.

[37] L. Genestier, M. Taillardet, P. Mondiere, H. Gheit, C. Bella, and T. Defrance, "TLR agonists selectively promote terminal plasma cell differentiation of B cell subsets specialized in thymus-independent responses," Journal of Immunology, vol. 178, no. 12, pp. 7779-7786, 2007.

[38] L. Lin, A. J. Gerth, and S. L. Peng, "CpG DNA redirects classswitching towards "Th1-like" Ig isotype production via TLR9 and MyD88," European Journal of Immunology, vol. 34, no. 5, pp. 1483-1487, 2004.

[39] W. Jiang, M. . M. Lederman, C. . V. Harding, B. Rodriguez, R. . J. Mohner, and S. . F. Sieg, "TLR9 stimulation drives naïve B cells to proliferate and to attain enhanced antigen presenting function," European Journal of Immunology, vol. 37, no. 8, pp. 2205-2213, 2007.

[40] K. N. Schmidt, B. Leung, M. Kwong et al., “APC-independent activation of NK cells by the toll-like receptor 3 agonist double-stranded RNA," Journal of Immunology, vol. 172, no. 1, pp. 138-143, 2004.
[41] L. Xie, R. Pries, R. Kesselring, S. Wulff, and B. Wollenberg, "Head and neck cancer triggers the internalization of TLR3 in natural killer cells," International Journal of Molecular Medicine, vol. 20, no. 4, pp. 493-499, 2007.

[42] K. S. Gorski, E. L. Waller, J. Bjornton-Severson et al., "Distinct indirect pathways govern human NK-cell activation by TLR-7 and TLR-8 agonists," International Immunology, vol. 18, no. 7, pp. 1115-1126, 2006.

[43] O. M. Hart, V. Athie-Morales, G. M. O’Connor, and C. M. Gardiner, "TLR7/8-mediated activation of human NK cells results in accessory cell-dependent IFN-gamma production," Journal of Immunology, vol. 175, no. 3, pp. 16361642, 2005.

[44] M. S. Sabel and V. K. Sondak, "Pros and cons of adjuvant interferon in the treatment of melanoma," The Oncologist, vol. 8, no. 5, pp. 451-458, 2003.

[45] R. T. Lester, X.-D. Yao, T. B. Ball et al., "Toll-like receptor expression and responsiveness are increased in viraemic HIV-1 infection," AIDS, vol. 22, no. 6, pp. 685-694, 2008.

[46] F. Ma, J. Zhang, J. Zhang, and C. Zhang, "The TLR7 agonists imiquimod and gardiquimod improve DC-based immunotherapy for melanoma in mice," Cellular \& Molecular Immunology, vol. 7, no. 5, pp. 381-388, 2010.

[47] H. Lu, Y. Yang, E. Gad et al., "TLR2 agonist PSK activates human NK cells and enhances the antitumor effect of HER2-targeted monoclonal antibody therapy," Clinical Cancer Research, vol. 17, no. 21, pp. 6742-6753, 2011.

[48] N. K. Crellin, R. V. Garcia, O. Hadisfar, S. E. Allan, T. S. Steiner, and M. K. Levings, "Human CD4+ T cells express TLR5 and its ligand flagellin enhances the suppressive capacity and expression of FOXP3 in CD4+CD25+ T regulatory cells," Journal of Immunology, vol. 175, no. 12, pp. 8051-8059, 2005.

[49] A. H. Rahman, D. K. Taylor, and L. A. Turka, "The contribution of direct TLR signaling to T cell responses," Immunologic Research, vol. 45, no. 1, pp. 25-36, 2009.

[50] A. Cottalorda, C. Verschelde, A. Marçais et al., "TLR2 engagement on CD8 T cells lowers the threshold for optimal antigen-induced T cell activation," European Journal of Immunology, vol. 36, no. 7, pp. 1684-1693, 2006.

[51] G. Caron, D. Duluc, I. Frémaux et al., "Direct stimulation of human T cells via TLR5 and TLR7/8: flagellin and R-848 up-regulate proliferation and IFN-gamma production by memory CD4+ T cells," Journal of Immunology, vol. 175, no. 3, pp. 1551-1557, 2005.

[52] Q. Li, Y. Yan, J. Liu et al., “Toll-like receptor 7 activation enhances CD8+ T cell effector functions by promoting cellular glycolysis," Frontiers in Immunology, vol. 10, 2019.

[53] N. Asprodites, L. Zheng, D. Geng, C. Velasco-Gonzalez, L. Sanchez-Perez, and E. Davila, "Engagement of toll-like receptor-2 on cytotoxic T-lymphocytes occurs in vivo and augments antitumor activity," The FASEB Journal, vol. 22, no. 10, pp. 3628-3637, 2008.

[54] D. Geng, L. Zheng, R. Srivastava, N. Asprodites, C. VelascoGonzalez, and E. Davila, "When toll-like receptor and T-cell receptor signals collide: a mechanism for enhanced CD8 Tcell effector function," Blood, vol. 116, no. 18, pp. 34943504, 2010.

[55] J. Tabiasco, E. Devêvre, N. Rufer et al., "Human effector CD8+ T lymphocytes express TLR3 as a functional coreceptor," Journal of Immunology, vol. 177, no. 12, pp. 8708-8713, 2006. 
[56] M. L. Salem, C. M. Diaz-Montero, S. A. el-Naggar, Y. Chen, O. Moussa, and D. J. Cole, "The TLR3 agonist poly(I:C) targets CD8+ T cells and augments their antigen-specific responses upon their adoptive transfer into naïve recipient mice," Vaccine, vol. 27, no. 4, pp. 549-557, 2009.

[57] G. Peng, "Toll-like receptor 8-mediated reversal of CD4+ regulatory T cell function," Science, vol. 309, no. 5739, pp. 13801384, 2005.

[58] R. P. Sutmuller, M. den Brok, M. Kramer et al., "Toll-like receptor 2 controls expansion and function of regulatory $\mathrm{T}$ cells," The Journal of Clinical Investigation, vol. 116, no. 2, pp. 485-494, 2006.

[59] H.-H. Oberg, T. T. H. Ly, S. Ussat, T. Meyer, D. Kabelitz, and D. Wesch, "Differential but direct abolishment of human regulatory T cell suppressive capacity by various TLR2 ligands," Journal of Immunology, vol. 184, no. 9, pp. 4733-4740, 2010.

[60] H. Liu, M. Komai-Koma, D. Xu, and F. Y. Liew, “Toll-like receptor 2 signaling modulates the functions of $\mathrm{CD} 4+$ CD25+ regulatory T cells," Proceedings of the National Academy of Sciences of the United States of America, vol. 103, no. 18, pp. 7048-7053, 2006.

[61] M. A. Anwar, M. Shah, J. Kim, and S. Choi, "Recent clinical trends in toll-like receptor targeting therapeutics," Medicinal Research Reviews, vol. 39, no. 3, pp. 1053-1090, 2019.

[62] K. K. Sahu and R. S. Pandey, "Immunological evaluation of colonic delivered hepatitis B surface antigen loaded TLR-4 agonist modified solid fat nanoparticles," International Immunopharmacology, vol. 39, pp. 343-352, 2016.

[63] J. Scheiermann and D. M. Klinman, "Clinical evaluation of $\mathrm{CpG}$ oligonucleotides as adjuvants for vaccines targeting infectious diseases and cancer," Vaccine, vol. 32, no. 48, pp. 6377-6389, 2014.

[64] F. P. B. Nunes, R. W. Alberca-Custódio, E. Gomes et al., "TLR9 agonist adsorbed to alum adjuvant prevents asthmalike responses induced by Blomia tropicalis mite extract," Journal of Leukocyte Biology, vol. 106, no. 3, pp. 653-664, 2019.

[65] C. M. Royer, K. Rudolph, G. N. Dietsch, R. M. Hershberg, and E. G. Barrett, "VTX-1463, a novel TLR-8 agonist, attenuates nasal congestion after ragweed challenge in sensitized beagle dogs," Immunity, Inflammation and Disease, vol. 4, no. 1, pp. 45-51, 2016.

[66] W. M. Hussein, T. Y. Liu, M. Skwarczynski, and I. Toth, "Toll-like receptor agonists: a patent review (2011-2013)," Expert Opinion on Therapeutic Patents, vol. 24, no. 4, pp. 453-470, 2014.

[67] S. Basith, B. Manavalan, T. H. Yoo, S. G. Kim, and S. Choi, "Roles of toll-like receptors in cancer: a double-edged sword for defense and offense," Archives of Pharmacal Research, vol. 35, no. 8, pp. 1297-1316, 2012.

[68] M. P. Simons, M. A. O'Donnell, and T. S. Griffith, Role of Neutrophils in BCG Immunotherapy for Bladder Cancer, In Urologic Oncology: Seminars and Original Investigations, Elsevier, 2008.

[69] F. Bianchi, S. Pretto, E. Tagliabue, A. Balsari, and L. Sfondrini, "Exploiting poly(I:C) to induce cancer cell apoptosis," Cancer Biology \& Therapy, vol. 18, no. 10, pp. 747756, 2017.

[70] T. Seya, Y. Takeda, and M. Matsumoto, "A toll-like receptor 3 (TLR3) agonist ARNAX for therapeutic immunotherapy," Advanced Drug Delivery Reviews, vol. 147, pp. 37-43, 2019.
[71] S. L. Lambert, C. F. Yang, Z. Liu et al., "Molecular and cellular response profiles induced by the TLR4 agonist-based adjuvant glucopyranosyl lipid A," PLoS One, vol. 7, no. 12, article e51618, 2012.

[72] H. Lu, J. Hewitt, and J. ter Meulen, "Intratumoral injection of G100 (TLR4 agonist glycopyranosyl lipid A) modulates tumor microenvironment and induces CD8 T cell-dependent, systemic anti-tumor immunity," AACR, 2016.

[73] G. J. Haderski, B. M. Kandar, C. M. Brackett et al., "TLR5 agonist entolimod reduces the adverse toxicity of TNF while preserving its antitumor effects," PLoS One, vol. 15, no. 2, article e0227940, 2020.

[74] V. Mett, E. A. Komarova, K. Greene et al., "Mobilan: a recombinant adenovirus carrying toll-like receptor 5 self-activating cassette for cancer immunotherapy," Oncogene, vol. 37, no. 4, pp. 439-449, 2018.

[75] C. J. de Witte, A. J. M. van de Sande, H. J. van Beekhuizen, M. M. Koeneman, A. J. Kruse, and C. G. Gerestein, "Imiquimod in cervical, vaginal and vulvar intraepithelial neoplasia: a review," Gynecologic Oncology, vol. 139, no. 2, pp. 377-384, 2015.

[76] D. Cunningham, IMPALA, a Randomized Phase III Study in Patients with Metastatic Colorectal Carcinoma: Immunomodulatory Maintenance Therapy with TLR-9 Agonist MGN1703, American Society of Clinical Oncology, 2015.

[77] J. K. Dowling and A. Mansell, "Toll-like receptors: the Swiss army knife of immunity and vaccine development," Clinical \& translational immunology, vol. 5, no. 5, article e85, 2016.

[78] A. Z. Dudek, C. Yunis, L. I. Harrison et al., "First in human phase I trial of $852 \mathrm{~A}$, a novel systemic toll-like receptor 7 agonist, to activate innate immune responses in patients with advanced cancer," Clinical Cancer Research, vol. 13, no. 23, pp. 7119-7125, 2007.

[79] R. Houot and R. Levy, "T-cell modulation combined with intratumoral CpG cures lymphoma in a mouse model without the need for chemotherapy," Blood, vol. 113, no. 15, pp. 3546-3552, 2009.

[80] J.-K. Li, TLR Agonists as Adjuvants for Cancer Vaccines, in Regulation of Inflammatory Signaling in Health and Disease, Springer, 2017.

[81] A. Marabelle, H. Kohrt, and R. Levy, "Intratumoral antiCTLA-4 therapy: enhancing efficacy while avoiding toxicity," Clinical Cancer Research, vol. 19, no. 19, pp. 5261-5263, 2013.

[82] H.-J. Schmoll, Maintenance Therapy with the TLR-9 Agonist MGN1703 in the Phase II IMPACT Study of Metastatic Colorectal Cancer Patients: A Subgroup with Improved Overall Survival, American Society of Clinical Oncology, 2015.

[83] H.-J. Schmoll, B. Wittig, D. Arnold et al., "Maintenance treatment with the immunomodulator MGN1703, a toll-like receptor 9 (TLR9) agonist, in patients with metastatic colorectal carcinoma and disease control after chemotherapy: a randomised, double-blind, placebo-controlled trial," Journal of Cancer Research and Clinical Oncology, vol. 140, no. 9, pp. 1615-1624, 2014.

[84] B. Wittig, M. Schmidt, W. Scheithauer, and H. J. Schmoll, "MGN1703, an immunomodulator and toll-like receptor 9 (TLR-9) agonist: from bench to bedside," Critical Reviews in Oncology/Hematology, vol. 94, no. 1, pp. 31-44, 2015.

[85] S. Agrawal and E. Kandimalla, Synthetic Agonists of Toll-Like Receptors 7, 8 and 9, Portland Press Ltd, 2007. 
[86] V. Hirsh, L. Paz-Ares, M. Boyer et al., "Randomized phase III trial of paclitaxel/carboplatin with or without PF-3512676 (toll-like receptor 9 agonist) as first-line treatment for advanced non-small-cell lung cancer," Journal of Clinical Oncology, vol. 29, no. 19, pp. 2667-2674, 2011.

[87] K. Kapp, J. Schneider, L. Schneider et al., "Distinct immunological activation profiles of $\mathrm{dSLIM}^{\circledR}$ and ProMune ${ }^{\circledR}$ depend on their different structural context," Immunity, Inflammation and Disease, vol. 4, no. 4, pp. 446-462, 2016.

[88] A. M. Krieg, "Toll-like receptor 9 (TLR9) agonists in the treatment of cancer," Oncogene, vol. 27, no. 2, pp. 161-167, 2008.

[89] C. Manegold, N. van Zandwijk, A. Szczesna et al., "A phase III randomized study of gemcitabine and cisplatin with or without PF-3512676 (TLR9 agonist) as first-line treatment of advanced non-small-cell lung cancer," Annals of Oncology, vol. 23, no. 1, pp. 72-77, 2012.

[90] D. A. Smith, P. Conkling, D. A. Richards et al., "Antitumor activity and safety of combination therapy with the toll-like receptor 9 agonist IMO-2055, erlotinib, and bevacizumab in advanced or metastatic non-small cell lung cancer patients who have progressed following chemotherapy," Cancer Immunology, Immunotherapy, vol. 63, no. 8, pp. 787-796, 2014.

[91] F. Sato-Kaneko, S. Yao, A. Ahmadi et al., "Combination immunotherapy with TLR agonists and checkpoint inhibitors suppresses head and neck cancer," JCI Insight, vol. 2, no. 18, 2017.

[92] M. J. Reilley, B. Morrow, C. R. Ager, A. Liu, D. S. Hong, and M. A. Curran, "TLR9 activation cooperates with T cell checkpoint blockade to regress poorly immunogenic melanoma," Journal for Immunotherapy of Cancer, vol. 7, no. 1, p. 323, 2019.

[93] M. C. Patra and S. Choi, "Recent progress in the development of toll-like receptor (TLR) antagonists," Expert Opinion on Therapeutic Patents, vol. 26, no. 6, pp. 719-730, 2016.

[94] F. Steinhagen, T. Kinjo, C. Bode, and D. M. Klinman, "TLRbased immune adjuvants," Vaccine, vol. 29, no. 17, pp. 33413355, 2011.

[95] M. Murata, "Activation of toll-like receptor 2 by a novel preparation of cell wall skeleton from Mycobacterium bovis BCG Tokyo (SMP-105) sufficiently enhances immune responses against tumors," Cancer Science, vol. 99, no. 7, pp. 14351440, 2008.

[96] M. Miyauchi, M. Murata, A. Fukushima et al., "Optimization of cell-wall skeleton derived from Mycobacterium bovis BCG Tokyo 172 (SMP-105) emulsion in delayed-type hypersensitivity and antitumor models," Drug Discoveries \& Therapeutics, vol. 6, no. 4, pp. 218-225, 2012.

[97] M. Reilly, R. M. Miller, M. H. Thomson et al., "Randomized, double-blind, placebo-controlled, dose-escalating phase I, healthy subjects study of intravenous OPN-305, a humanized anti-TLR2 antibody," Clinical Pharmacology and Therapeutics, vol. 94, no. 5, pp. 593-600, 2013.

[98] R. Ammi, J. De Waele, Y. Willemen et al., "Poly(I:C) as cancer vaccine adjuvant: knocking on the door of medical breakthroughs," Pharmacology \& Therapeutics, vol. 146, pp. 120131, 2015.

[99] M. M. Melssen, G. R. Petroni, K. A. Chianese-Bullock et al., "A multipeptide vaccine plus toll-like receptor agonists LPS or polyICLC in combination with incomplete Freund's adju- vant in melanoma patients," Journal for Immunotherapy of Cancer, vol. 7, no. 1, p. 163, 2019.

[100] H. Navabi, B. Jasani, A. Reece et al., "A clinical grade poly I:C-analogue (Ampligen ${ }^{\circledR}$ ) promotes optimal DC maturation and Th1-type $\mathrm{T}$ cell responses of healthy donors and cancer patients in vitro," Vaccine, vol. 27, no. 1, pp. 107115, 2009.

[101] G. Panter, A. Kuznik, and R. Jerala, "Therapeutic applications of nucleic acids as ligands for toll-like receptors," Current Opinion in Molecular Therapeutics, vol. 11, no. 2, pp. 133$145,2009$.

[102] Y. Takeda, S. Yoshida, K. Takashima et al., "Vaccine immunotherapy with ARNAX induces tumor-specific memory T cells and durable anti-tumor immunity in mouse models," Cancer Science, vol. 109, no. 7, pp. 2119-2129, 2018.

[103] M. Matsumoto, Y. Takeda, M. Tatematsu, and T. Seya, "Tolllike receptor 3 signal in dendritic cells benefits cancer immunotherapy," Frontiers in Immunology, vol. 8, 2017.

[104] C. D. Romero, T. K. Varma, J. B. Hobbs, A. Reyes, B. Driver, and E. R. Sherwood, "The toll-like receptor 4 agonist monophosphoryl lipid a augments innate host resistance to systemic bacterial infection," Infection and Immunity, vol. 79, no. 9, pp. 3576-3587, 2011.

[105] R. N. Coler, The TBVPX-113 Study Team, T. A. Day et al., "The TLR-4 agonist adjuvant, GLA-SE, improves magnitude and quality of immune responses elicited by the ID93 tuberculosis vaccine: first-in-human trial," NPJ Vaccines, vol. 3, no. 1, 2018.

[106] A. M. Didierlaurent, S. Morel, L. Lockman et al., "AS04, an aluminum salt- and TLR4 agonist-based adjuvant system, induces a transient localized innate immune response leading to enhanced adaptive immunity," Journal of Immunology, vol. 183, no. 10, pp. 6186-6197, 2009.

[107] M. S. Oba, S. Teramukai, Y. Ohashi, K. Ogawa, Y. Maehara, and J. Sakamoto, "The efficacy of adjuvant immunochemotherapy with OK-432 after curative resection of gastric cancer: an individual patient data meta-analysis of randomized controlled trials," Gastric Cancer, vol. 19, no. 2, pp. 616624, 2016.

[108] S. Federico, L. Pozzetti, A. Papa et al., "Modulation of the innate immune response by targeting toll-like receptors: a perspective on their agonists and antagonists," Journal of Medicinal Chemistry, vol. 63, no. 22, pp. 13466-13513, 2020.

[109] F. Horak, "VTX-1463, a novel TLR8 agonist for the treatment of allergic rhinitis," Expert Opinion on Investigational Drugs, vol. 20, no. 7, pp. 981-986, 2011.

[110] C. S. Zent, B. J. Smith, Z. K. Ballas et al., "Phase I clinical trial of CpG oligonucleotide 7909 (PF-03512676) in patients with previously treated chronic lymphocytic leukemia," Leukemia \& Lymphoma, vol. 53, no. 2, pp. 211-217, 2012.

[111] J.-P. Machiels, M.-C. Kaminsky, U. Keller et al., "Phase Ib trial of the toll-like receptor 9 agonist IMO-2055 in combination with 5-fluorouracil, cisplatin, and cetuximab as first-line palliative treatment in patients with recurrent/metastatic squamous cell carcinoma of the head and neck," Investigational New Drugs, vol. 31, no. 5, pp. 1207-1216, 2013.

[112] S. Wang, J. Campos, M. Gallotta et al., "Intratumoral injection of a $\mathrm{CpG}$ oligonucleotide reverts resistance to $\mathrm{PD}-1$ blockade by expanding multifunctional CD8+ T cells," Proceedings of the National Academy of Sciences of the United States of America, vol. 113, no. 46, pp. E7240-E7249, 2016. 
[113] E. Vacchelli, N. Bloy, F. Aranda et al., "Trial Watch: immunotherapy plus radiation therapy for oncological indications," Oncoimmunology, vol. 5, no. 9, article e1214790, 2016.

[114] D. Babaer, S. Amara, B. S. McAdory et al., "Oligodeoxynucleotides ODN 2006 and M362 exert potent adjuvant effect through TLR-9/-6 synergy to exaggerate mammaglobin-A peptide specific cytotoxic $\mathrm{CD} 8+\mathrm{T}$ lymphocyte responses against breast cancer cells," Cancers (Basel), vol. 11, no. 5, p. $672,2019$.

[115] J. Jie, Y. Zhang, H. Zhou et al., "CpG ODN1826 as a promising mucin1-maltose-binding protein vaccine adjuvant induced DC maturation and enhanced antitumor immunity," International Journal of Molecular Sciences, vol. 19, no. 3, p. 920, 2018.

[116] N. R. Anderson, N. G. Minutolo, S. Gill, and M. Klichinsky, "Macrophage-based approaches for cancer immunotherapy," Cancer Research, vol. 81, no. 5, pp. 1201-1208, 2021.

[117] S. Anguille, E. L. Smits, E. Lion, V. F. van Tendeloo, and Z. N. Berneman, "Clinical use of dendritic cells for cancer therapy," The Lancet Oncology, vol. 15, no. 7, pp. e257e267, 2014.

[118] F. Fang, W. Xiao, and Z. Tian, "NK cell-based immunotherapy for cancer," Seminars in Immunology, vol. 31, pp. 3754, 2017.

[119] S. A. Feldman, Y. Assadipour, I. Kriley, S. L. Goff, and S. A. Rosenberg, "Adoptive cell therapy-tumor-infiltrating lymphocytes, T-cell receptors, and chimeric antigen receptors," Seminars in Oncology, vol. 42, no. 4, pp. 626-639, 2015.

[120] M. Basiri and S. Pahlavanneshan, "Evaluation of ALPP as a potential target for immunotherapy of solid tumors using gene and protein expression repositories," Cell J, 2021.

[121] M.-H. Haddadi, E. Hajizadeh-Saffar, M. Khosravi-Maharlooei, M. Basiri, B. Negahdari, and H. Baharvand, "Autoimmunity as a target for chimeric immune receptor therapy: a new vision to therapeutic potential," Blood Reviews, vol. 41, p. $100645,2020$.

[122] R. Weinkove, P. George, N. Dasyam, and A. D. McLellan, "Selecting costimulatory domains for chimeric antigen receptors: functional and clinical considerations," Clinical \& Translational Immunology, vol. 8, no. 5, p. e1049, 2019.

[123] C. M. Kowolik, M. S. Topp, S. Gonzalez et al., "CD28 costimulation provided through a CD19-specific chimeric antigen receptor enhances in vivo persistence and antitumor efficacy of adoptively transferred T cells," Cancer Research, vol. 66, no. 22, pp. 10995-11004, 2006.

[124] Y. Lai, J. Weng, X. Wei et al., “Toll-like receptor 2 costimulation potentiates the antitumor efficacy of CAR T cells," Leukemia, vol. 32, no. 3, pp. 801-808, 2018.

[125] M. R. Collinson-Pautz, W.-C. Chang, A. Lu et al., "Constitutively active MyD88/CD40 costimulation enhances expansion and efficacy of chimeric antigen receptor $\mathrm{T}$ cells targeting hematological malignancies," Leukemia, vol. 33, no. 9, pp. 2195-2207, 2019.

[126] A. E. Foster, A. Mahendravada, N. P. Shinners et al., "Regulated expansion and survival of chimeric antigen receptormodified $\mathrm{T}$ cells using small molecule-dependent inducible MyD88/CD40," Molecular Therapy, vol. 25, no. 9, pp. 2176-2188, 2017.

[127] A. S. Davey, M. E. Call, and M. J. Call, "The influence of chimeric antigen receptor structural domains on clinical outcomes and associated toxicities," Cancers, vol. 13, no. 1, 2021.
[128] X. Wang, D. L. Jasinski, J. L. Medina, D. M. Spencer, A. E. Foster, and J. H. Bayle, "Inducible MyD88/CD40 synergizes with IL-15 to enhance antitumor efficacy of CAR-NK cells," Blood Advances, vol. 4, no. 9, pp. 1950-1964, 2020.

[129] E. J. Velazquez, "Macrophage toll-like receptor-chimeric antigen receptors (MOTO-CARs) as a novel adoptive cell therapy for the treatment of solid malignancies," Cancer Research, vol. 78, pp. 2563-2563, 2018.

[130] M. H. Townsend, "MOTO-CARs" : a novel macrophagebased chimeric antigen receptor technology," Cancer Research, vol. 80, pp. 3254-3254, 2020.

[131] S. Di, M. Zhou, Z. Pan et al., "Combined adjuvant of poly I:C improves antitumor effects of CAR-T cells," Frontiers in Oncology, vol. 9, p. 241, 2019.

[132] T. N. Pham, C. Y. Hong, J. J. Min et al., "Enhancement of antitumor effect using dendritic cells activated with natural killer cells in the presence of toll-like receptor agonist," Experimental \& Molecular Medicine, vol. 42, no. 6, pp. 407$419,2010$.

[133] J. J. Freen-van Heeren, “Toll-like receptor-2/7-mediated T cell activation: an innate potential to augment CD8(+) T cell cytokine production," Scandinavian Journal of Immunology, vol. 93, 2021.

[134] Q. Guo and C. Zhang, "Critical role of toll-like receptor signaling in NK cell activation," Chinese Science Bulletin, vol. 57, no. 24, pp. 3192-3202, 2012.

[135] G. Schreibelt, J. Tel, K. H. E. W. J. Sliepen et al., "Toll-like receptor expression and function in human dendritic cell subsets: implications for dendritic cell-based anti-cancer immunotherapy," Cancer Immunology, Immunotherapy, vol. 59, no. 10, pp. 1573-1582, 2010.

[136] Q. Zeng and C. M. Jewell, "Directing toll-like receptor signaling in macrophages to enhance tumor immunotherapy," Current Opinion in Biotechnology, vol. 60, pp. 138-145, 2019.

[137] M. Smith, E. García-Martínez, M. R. Pitter et al., "Trial Watch: toll-like receptor agonists in cancer immunotherapy," Oncoimmunology, vol. 7, no. 12, article e1526250, 2018.

[138] A. Pavlick, A. B. Blazquez, M. Meseck et al., "Combined vaccination with NY-ESO-1 protein, poly-ICLC, and montanide improves humoral and cellular immune responses in patients with high-risk melanoma," Cancer Immunology Research, vol. 8, no. 1, pp. 70-80, 2020.

[139] C. L. Slingluff Jr., G. R. Petroni, W. C. Olson et al., "A randomized pilot trial testing the safety and immunologic effects of a MAGE-A3 protein plus AS15 immunostimulant administered into muscle or into dermal/subcutaneous sites," Cancer Immunology, Immunotherapy, vol. 65, no. 1, pp. 25-36, 2016.

[140] G. Shayan, B. A. Kansy, S. P. Gibson et al., "Phase Ib study of immune biomarker modulation with neoadjuvant cetuximab and TLR8 stimulation in head and neck cancer to overcome suppressive myeloid signals," Clinical Cancer Research, vol. 24, no. 1, pp. 62-72, 2018.

[141] L. Q. M. Chow, C. Morishima, K. D. Eaton et al., "Phase Ib trial of the toll-like receptor 8 agonist, motolimod (VTX2337), combined with cetuximab in patients with recurrent or metastatic SCCHN," Clinical Cancer Research, vol. 23, no. 10, pp. 2442-2450, 2017.

[142] S. Mehrotra, C. D. Britten, S. Chin et al., "Vaccination with poly(IC:LC) and peptide-pulsed autologous dendritic cells in patients with pancreatic cancer," Journal of Hematology \& Oncology, vol. 10, no. 1, p. 82, 2017. 
[143] C. P. Belani, B. C. Chakraborty, R. I. Modi, and B. M. Khamar, "A randomized trial of TLR-2 agonist CADI-05 targeting desmocollin-3 for advanced non-small-cell lung cancer," Annals of Oncology, vol. 28, no. 2, pp. 298-304, 2017.

[144] L. G. Salazar, H. Lu, J. L. Reichow et al., “Topical imiquimod plus nab-paclitaxel for breast cancer cutaneous metastases: a phase 2 clinical trial," JAMA Oncology, vol. 3, no. 7, pp. 969-973, 2017.

[145] R. Ronsley, A. Kariminia, B. Ng et al., "The TLR9 agonist (GNKG168) induces a unique immune activation pattern in vivo in children with minimal residual disease positive acute leukemia: results of the TACL T2009-008 phase I study," Pediatric Hematology and Oncology, vol. 36, no. 8, pp. 468-481, 2019. 